\title{
Las interacciones entre la Compañía de Jesús y los vecinos de Santiago. Apoyo y enfrentamiento en los primeros años de la orden en Chile (1593-1647)
}

\author{
Eduardo Gutiérrez Ramírez ${ }^{1}$ \\ Recibido: 10 de septiembre de 2017 - Aprobado: 27 de octubre de 2017
}

\begin{abstract}
Resumen
En el presente trabajo se analiza la interacción entre jesuitas y vecinos de Santiago, durante los primeros años de la Compañía en el territorio. Asimismo, se analiza de qué manera la Guerra Defensiva habría influenciado la percepción que en Santiago se tenía de la orden, y cómo esto ayudó o dificultó la actividad jesuita durante sus inicios en Chile. Las fuentes utilizadas en este trabajo corresponden al fondo jesuitas de Chile, así como a recopilaciones de documentos extranjeros relacionados con la estadía jesuita en Chile. La investigación se ha realizado considerando a la Compañía de Jesús en su calidad de vecino, compartiendo con el resto de los vecinos de la ciudad, concluyendo que la relación entre ambos grupos fue fundamental en el rápido posicionamiento de la orden.
\end{abstract}

Palabras clave: Compañía de Jesús, Luis de Valdivia, Guerra defensiva, vecinos.

Interactions between the Society of Jesus and neighbors at Santiago. Support and confrontation in the order's first years in Chile (1593-1647)

\begin{abstract}
The present work analyzes the interactions between Jesuits and neighbors at Santiago, during the Society's first years in the territory. Likewise, it explores how the Defensive War would have influenced the perception of the order at Santiago and how this helped or hindered the Jesuit activity during its beginnings in Chile. Sources used in this work correspond to the Jesuit fund of Chile, as well as to compilations of foreign documents related to the Jesuit work in Chile. The research has been carried out considering the Society of Jesus as a neighbor - sharing with the rest of the city's neighbors - conclud-
\end{abstract}

1 Chileno. Magíster en Historia, Universidad Nacional Andrés Bello. E-mail: edu.agr@gmail.com 
ing that the relationship between both groups was fundamental in the rapid positioning of the order.

Keywords: Society of Jesus, Luis de Valdivia, Defensive War, neighbors.

\title{
As interações entre a Companhia de Jesus e os vizinhos de Santiago. Apoio e confronto nos primeiros anos da ordem no Chile (1593-1647)
}

\begin{abstract}
Resumo
No presente trabalho, analisa-se a interação entre jesuítas e vizinhos de Santiago, durante os primeiros anos da Companhia no território. Do mesmo modo, analisa-se como a Guerra Defensiva teria influenciado a percepção que em Santiago tinha-se sobre a ordem, e como isso ajudou ou impediu a atividade dos jesuítas durante seus inícios no Chile. As fontes utilizadas neste trabalho correspondem ao Fundo jesuítas do Chile, bem como a compilações de documentos estrangeiros relacionados com a estadia jesuíta no Chile. A investigação foi realizada considerando a Companhia de Jesus em sua qualidade de vizinho, compartilhando com o resto dos vizinhos da cidade, concluindo que a relação entre ambos grupos foi fundamental no rápido posicionamento da ordem.
\end{abstract}

Palavras-chave: Companhia de Jesus, Luís de Valdivia, guerra defensiva, vizinhos.

Este artículo tiene como objetivo comprender la interacción entre los jesuitas y los vecinos de Santiago. La relación que se desarrolló entre ambos grupos resulta fundamental para poder entender la velocidad y eficacia con que la Compañía de Jesús se asentó en el territorio chileno, así como las acciones que ésta tomará a futuro. De esta forma, revisar los primeros años de la orden ignaciana en Chile nos presenta un escenario ideal para observar algunas de las lógicas sociales utilizadas por la Compañía, así como la recepción que estas tuvieron en Santiago. Para esto, se analizarán los primeros 30 años de la orden en Chile, desde su llegada hasta los primeros años de la Guerra Defensiva, considerando esta última como un hecho fundamental dentro de la historia de la relación entre jesuitas y vecinos.

El 12 de abril de 1593 la Compañía de Jesús arribó a territorio chileno. El grupo conformado por ocho jesuitas había partido desde el puerto de El Callao dos meses antes y llegaron con la misión de ayudar con la evangelización del sur del territorio. Originalmente, se les había ordenado no fundar ningún colegio, ni asentarse en ninguna ciudad. Según lo explica el Provincial Pablo de Arriaga, en la carta anua enviada al General Claudio Aquaviva, se les había recomendado esto: 
"por ser toda la tierra de Chile muy pobre de plata y estar toda la gente muy gastada con las continuas guerras que de tantos años hasta ora continuamente trahen, como en la del año que viene, siendo Dios nuestro Señor servido, daré larga relación con las costumbres de la tierra y descubrimiento y naturaleza della, se proveyeron, quanto ser pudo, de libros, ornamentos y de las demás cosas que para hazer asiento y poblar una residencia o colegio era necessario, aunque por entonces no llevavan intento dello, echos a la vela para tan grande empresa como acometieron de la conquista de tantas naciones como en aquellas partes ay" (Egaña, 1970: 457).

Así, deberían haber viajado lo antes posible al sur para comenzar la evangelización de los naturales, componiendo una suerte de misión ambulante. Pero a la vez, y ese es el detalle importante, señala Arriaga que los padres venían de todas formas preparados en caso de ser necesaria alguna fundación más estable, lo cual fue, más adelante, apoyado por los vecinos de Santiago.

Ante lo que informaba Arriaga en su carta, en la que también menciona la efectiva fundación del Colegio en 1593, responde el General Aquaviva que "...no me huelgo poco que el buen Padre Piñas aya emprendido la de Chile, porque se buen exemplo despertará a otros..." (Egaña, 1970: 538). De tal forma, en principio el General aceptaría la fundación del Colegio, en especial ya que el padre Piñas estaría a cargo del grupo. Sin embargo, al año siguiente de la fundación del Colegio, el sacerdote se retiró al Perú y el rectorado le fue encargado a Luis de Valdivia, quien informó, en 1595, al Padre General de cómo se desarrollaba el Colegio. El Padre (P.) Aquaviva contestaría a esta carta en 1597, expresando que:

"Por una de V. R. escrita el Marzo del 95 entiendo el buen empleo de los Nuestros en la missión del Chile, donde, según el Padre Provincial me escribe, al fin han aceptado collegio. Plegue al Señor que sea para su gloria y útil de esa gente, que aunque yo deseo que los Nuestros atiendan al bien de los naturales, no querría que abraçásemos más de lo que se puede bien cultivar" (Egaña, 1974, 167).

Efectivamente, y como se señala con la última frase, una de las mayores preocupaciones del padre Aquaviva era que, por la atención que se debía poner en el Colegio, se dejase de lado la misión original de evangelizar paganos. Junto con esto, es probable que la confianza inicial que demostraba en el padre Piñas, ahora se pusiera en duda por el cambio de rector y la partida del sacerdote.

Por otra parte, San Ignacio, fundador de la orden, y su círculo cercano, veían a los colegios como una extensión de la evangelización (O'Malley, 199: 
248-151), por lo que tampoco sería correcto negar la posibilidad de establecer uno en una tierra tan alejada como Chile. De tal forma, a pesar de los resquemores del General, no se habrían presentado mayores inconvenientes en el establecimiento del colegio, debido a que fue tan bien aceptado por los vecinos de Santiago, y así lo relata la Histórica Relación elaborada tras la expulsión de la orden, en la que se señala que:

"Compraron en ella en una quadra a distancia de su Plaza Mayor, las Casas que fueron de un Gobernador en tres mil seiscientos pesos y algunas alaxas para el Culto Divino, con las limosnas que les hizo el Vezindario, siendo sus principales benecfactores Don Andres, Torquemada, y Don Agustin Brizeño, quienes con eficaces deseos de su establecimiento dieron fundos para la fundacion de un Colegio con la vocacion de San Miguel". ${ }^{2}$

De esta manera, los vecinos esperaban que los jesuitas fundaran un colegio en el territorio, sin duda, debido a la fama que estos tenían y desde un comienzo aportaron importantes fondos para la construcción del mismo. La intervención de los habitantes de Santiago fue fundamental en la creación del Colegio.

\section{La ciudad de Santiago y el Colegio jesuita}

En una carta enviada por el padre Piñas tras su llegada a Santiago, relata lo sucedido en el cabildo eclesiástico, en el que los jesuitas explicaron sus intenciones en Chile. Aquí, informa el sacerdote que:

"Pasada la Pascua de Resurrectión se comenzó a tratar de nuestro asiento, juntáronse una tarde en el Cabildo seglar y eclesiástico, en la Iglesia mayor, y imbiáronme a llamar; hablé otra vez a los presentes más em particular del Instituto, fin y pretensión de la Compañía, y al fin de mi raçonamiento, les dije que antes que del Pirú saliésemos, savíamos bien quán pobre y gastada estava la tierra, y que ansí veníamos bien prevenidos para trabajos, y que ésta havía de ser una missión, mientras la ciudad no diese tal traza que obligase a otra cosa y que la missión no era de dura[ción] sino por algunos años". (Egaña, 1970: 464).

De tal forma, Piñas explica cómo su intención inicial era no permanecer fijos en ninguna parte, ni asentar de manera estable a la Compañía, sino sólo cumplir su misión de evangelizadores por el tiempo que fuera necesario,

2 "Histórica Relación del Colegio de San Miguel", en Archivo Nacional Histórico de Chile (ANHCh), Fondo Jesuitas de Chile, vol. 39, ff. 171 - 171v. 
argumentando cómo la pobreza de la provincia no permitiría mantener una Casa o un Colegio. Ante esto, continúa Piñas, los vecinos de Santiago se habrían manifestado en contra de sus ideas, reclamando que:

"estávamos acá y que no havía que tratar de missión ad tempus, sino de asentar para siempre, que ellos nos querían perpetuar, haciendo lo posible, como lo veríamos y havíanos dicho algunos amigos nuestros, y entre ellos todos los religiosos por cosa cierta; que quando más nos quisiesen dar entre todos, serían hasta mil ducados en oro." (Egaña, 1970: 464).

Se relata que existe un importante interés por parte de los vecinos para mantener a la Compañía en Santiago y que trabajen dentro de la ciudad. Los donativos no se hicieron esperar, y con el dinero que se juntó lograron comprar la casa que había pertenecido a Rodrigo de Quiroga, a una cuadra de la plaza de armas. ${ }^{3}$ En el memorial de los donativos al Colegio, de abril de 1593, se reúnen un total de 116 donaciones, que van desde los 2 hasta los 800 pesos, con los cuales los jesuitas lograron reunir un total de 3.298 pesos. De tal manera se señala en la escritura de venta de la casa, el 12 de mayo de 1593:

"...e por precio e quantía de tres mill e seiscientos pesos de oro de contrato, fundido y marcado con la real marca de Su Magestad, de ciete quilates y medio, que por compra de las dichas cassas me a dado el dicho Padre Rector y los demás vezinos de la dicha ciudad, de que yo me doy por vien contento, pagado y entregado a toda mi boluntad" (Egaña, 1970: 267-268).

Como se puede notar, desde un comienzo se entiende la creación del Colegio Máximo como una obra perteneciente a los jesuitas, pero en la cual la ciudad en su conjunto se encuentra envuelta, pues es gracias a los vecinos que se logra adquirir el primer establecimiento, y por un precio bastante elevado. También es interesante señalar quiénes son algunos de los vecinos que donan y las cantidades que entregan. Así, por ejemplo, Jerónimo de Molina, quien realizaría la donación más alta, equivalente a 200 pesos (ya de por sí elevado) más una casa que perteneciera a su hermano (Egaña, 1970, 256), fue juez mayor de bienes de difuntos $y$, posteriormente, corregidor de Santiago. Por otra parte, Luis Jofré, quien donara 150 pesos, es señalado como fundador de la ciudad de San Luis de Loyola y posteriormente es nombrado maestre de campo general del reino. Otro donador importante sería Alonso de Córdova, quien donara 200 pesos en ropa y a quien otro

3 Corresponde a las actuales dependencias del ex-Congreso Nacional, en la esquina de las calles Compañía de Jesús y Bandera. 
donador, Jerónimo de Benavides, también nombró como referencia de su propia donación (Egaña, 1970: 256).

De tal manera, es claro que los vecinos se sintieron involucrados con la creación del Colegio. Prácticamente todos los donadores habían cumplido algún cargo municipal en Santiago, por lo que involucrarse de manera activa en el establecimiento de la institución les significaba una nueva inversión para su ciudad y para ellos. Pero al mismo tiempo, no sólo existe una necesidad por donar y demostrar, ante los otros vecinos, la valía personal al interior de la ciudad, sino que existe también una necesidad por sentirse parte de la misma ciudad y de lo que en ella se elabora. Así parecen señalarlo las donaciones ínfimas (algunas de dos o cuatro pesos) que aparecen en el memorial, las cuales, realmente, no aportan en gran medida al pozo final que se logra reunir, pero que aun así les permite a sus donadores ser parte de la fundación. Con esto, el Colegio ya no sería sólo una institución jesuita, sino una institución de Santiago. Es importante destacar este punto pues, a diferencia de otros colegios jesuitas que se fundaron en América, el de Santiago no estaba dentro de las órdenes que tenían los jesuitas. Mientras que fundaciones más importantes como el colegio de Lima o las reducciones en Paraguay formaban parte de los planes de la orden, el de Santiago fue una iniciativa conjunta con los vecinos de Santiago, lo que hace que estos sean partícipes directos del mismo.

Dentro de los vecinos que donaron al Colegio, el título de "fundador" le fue entregado sólo a dos, debido al nivel de los aportes que estos entregaron: Agustín Briseño y Andrés de Torquemada. Briseño, quien había llegado a Chile en 1558, había tenido una importante carrera en el territorio, sirviendo como notario y como soldado, bajo las órdenes de Pedro de Villagra y luego de Rodrigo de Quiroga. Poco antes de la llegada de los jesuitas había servido como regidor y como alcalde, conformándose entonces como un personaje notable al interior de Santiago (Medina, 1906, 144). Su donación fue realizada en octubre de 1595, entregando a la Compañía una viña con la casa que en ella había, avaluada en 3400 pesos y, de esta manera, daría una renta de 200 pesos anuales, donación que sumada a la anterior, daba un total de 6200 pesos. Lamentablemente, para el capitán, le fue imposible cumplir con lo prometido, debiendo más de 3600 pesos a la hora de su muerte. Debido a esto, renunciaría a su calidad de fundador en agosto de 1600, declarando:

"conforme a la escrixtura de fundacion me contento con haver sido venefactor del dicho colegio y pido y supplico a mis superiores que no me admitan a mi por fundador pues asi lo dice La escritura de fundacion [que yo] cuanto es de mi parte çedo y renunsio cualquier dho que a ello tenga y dejo dicho a la compañia de jessus para que a su adbitrio pueda admitir otro compañero de fundacion con andres de 
torquemada Vazquez o me contento con morir en hermano religiosso de la esta conpañia". ${ }^{4}$

Resulta interesante la manera en que Briseño entiende su participación en el colegio, pues no se interesa más por dejar constancia de su importancia en la fundación del mismo (después de todo fue uno de los principales donadores en un comienzo), y, además, se contenta con ser reconocido por la orden como benefactor y como hermano. Sería erróneo señalar que la importancia que el capitán le da a la Compañía pueda ser influenciada por el colegio, sobre todo porque él no estudió ahí, pero indudablemente es una primera señal de cómo la orden ganaba apoyo e importancia dentro de la esfera santiaguina. Junto con eso, también se dejó libre el puesto del segundo fundador, así como lo pidió Briseño, para quien pudiera aportar más a la orden; puesto que sería ocupado casi 50 años después por Gerónimo Madureira, quien ayudaría a la reconstrucción del colegio tras el terremoto de 1647. El otro fundador, Andrés de Torquemada, sí lograría retener el título, pues su donación fue muy superior a la de Briseño, incluso aunque éste hubiese podido pagarla en su totalidad.

Torquemada, natural de Córdoba y reputado vecino de la ciudad de Santiago de Chile, al no tener herederos, designó a la Compañía como su heredera universal, entregando todo lo que tenía a esta para la fundación del Colegio Máximo. Esta donación correspondía a una casa y una viña, con todo lo que en ella había plantado y construido, una estancia que tenía a dos leguas de la ciudad, con el ganado que en ella había, y siete esclavos, cuatro negros y tres negras, de los cuales por morir dos de los hombres, reemplazó con otros dos más jóvenes. De toda esta donación, él podría seguir usufructuando lo entregado por la viña hasta el día de su muerte, la que llegaría en 1604, con lo que la Compañía podría tomar posesión efectiva de ellas tras esto; asimismo, la orden podría recibir de inmediato el usufructo de la estancia y hacer uso de los esclavos sin ninguna retención ${ }^{5}$. Así también, habría donado un total de 50 cuadras de tierra, a una legua de la ciudad, al otro lado del río. ${ }^{6}$

Señala Torquemada que todos estos bienes los dona para "...questa sancta compañia vaia en aumento y porque tiene necesidad el dicho colejio para se poder sustentar en aquella via y forma que mejor lugar aya..." 7 . Nuevamente se puede notar la importancia que los donadores dan a la fundación de este colegio y a la presencia de la Compañía en la ciudad. En parte, esto sin duda

4 ANHCh, Fondo Jesuitas de Chile, vol. 124, f. 64

5 ANHCh, Fondo Jesuitas de Chile, vol. 124, f. 26.

6 ANHCh, Fondo Jesuitas de Chile, vol. 119, f. 81.

7 ANHCh, Fondo Jesuitas de Chile, vol. 124, f. 26. 
se debe a que ellos mismos ven aumentado su prestigio al ensalzar la labor de la orden, pero también es posible entenderlo como la penetración que las ideas de la Compañía han tenido en unos pocos años.

Con la casa de Quiroga comprada, se iniciaron una serie de clases para la población de Santiago, que ayudó a afianzar la relación entre la orden y los vecinos. La primera fue una clase de gramática impartida por el padre Olivares y, posteriormente, una de retórica. Para 1594 habían también agregado una cátedra de Artes (filosofía), impartida por el padre Valdivia, que se convirtió en la primera estable en el territorio, y a la que no sólo asistían miembros de la orden, sino también franciscanos, dominicos, mercedarios y seglares (Hanisch, 1974: 8; Enrich, 1891: 33 -34). Para julio de ese año, el padre Valdivia informaba que: "Aunque quedamos solo quatro Padres aquí por tres meses, se acudió bien a todo y se puso el curso de Artes y en lo temporal de la iglesia se a hecho mucho, de modo que para San Miguel nos pasaremos a ella." (Egaña, 1974: 268); por lo que para fines de septiembre es posible asumir que el colegio se encontraba en pleno uso.

Por esta misma época, se daría inicio a la biblioteca del Colegio. En la misma carta ya citada, Valdivia, que para ese momento era rector del Colegio Máximo, pide que le envíen desde el Perú "los Xuárez, Belarminos; acá está el $1^{\circ}$ tomo de Belarmino, Osorios, Padre Pereyra, Padre Toledo sobre San Juan, obras de Santo Thomas, y los predicatorios que Vuestra Reverencia Jusgare; si quiere lance algunos buenos Augustinos" (Egaña, 1974: 267), en lugar de un dinero que se les adeuda. Esta es la primera muestra de parte de los jesuitas en Chile por elaborar una biblioteca, y, asimismo, por la preocupación que le dieron a la lectura durante sus años en el territorio, prefiriéndolos al dinero. Un ejemplo similar es posible hallarlo algunos años después, ya en el contexto de la Guerra Defensiva, en un momento en que el P. Valdivia solicitó un permiso al Rey "...para que pueda embarcar en el navio donde fuere una libreria que ha comprado para si y sus compañeros por la falta que hay en la tierra de guerra de libros". Asimismo, las bibliotecas jesuitas, propias de la época en que se fundó la orden, se encontraban plagadas de libros de las más diferentes materias, y será posible encontrar en ellas distintos libros y temáticas dependiendo de las necesidades propias de cada colegio y biblioteca (De Tezanos, 2014: 123 - 124). Para la Compañía, y sobre todo para los jesuitas chilenos, el libro jugó un papel fundamental en la evangelización, lo que explica de cierta forma la importancia que la biblioteca del Colegio Máximo tomaría durante la colonia, y luego de esta (Gutiérrez, 2014).

\section{El rector Luis de Valdivia}

La carta de Valdivia solicitando libros fue sólo una de las tantas comunicaciones que el sacerdote tuvo con el Perú, con Roma y con España en los 
primeros años del Colegio. Valdivia, como rector durante los primeros nueve años, fue el responsable de conectar a la institución con Santiago, y a la vez fue quien dictara los primeros lineamientos. Por esto, es necesario referirse brevemente a Luis de Valdivia.

Valdivia había ingresado a la Compañía en 1581 y en 1588 solicitó permiso al Padre General Aquaviva para poder viajar a América y así ayudar a la evangelización de los indígenas. Este deseo no resultaba extraño en jesuitas jóvenes o recién ordenados, quienes esperaban poder servir a la orden y a Dios de la mejor manera posible. Como ha señalado Gaune, si bien no siempre sabían dónde serían enviados, se ansiaban las misiones alejadas y de mayor riesgo, donde, sentían, podrían sus actos ser de mayor utilidad (Gaune, 2011: 298-301). Esto le fue finalmente permitido y se unió a la expedición del Padre Diego de Mendoza. Llegó en 1589, y sirvió en el Perú hasta que fue enviado a Chile bajo el mando del Padre Baltasar de Piñas junto con sus compañeros (Díaz, 2011: 25-29).

Durante el viaje, según relata el mismo Valdivia, una tormenta azotó el barco en que viajaban y, en un momento de desesperación, Valdivia realizaría una promesa que marcaría su estancia en Chile: "Llamamos con ansias a Jesús, y yo hice de la necesidad virtud, ofreciendo mi vida por la conversión del valle de Arauco" (Egaña, 1970: 459). Considerando que a su llegada al territorio Valdivia fue encargado al trabajo con los indígenas (Kort, 1968: 81), la relación del viaje se entiende en un contexto en el cual el sacerdote intenta explicar su accionar guiado por Dios, y a la vez validar sus ideas en torno a los indios, lo que en años posteriores se vería de manera clara. Asimismo, evitando el "lugar común" señalado por Gaune (2013: 19), refiriéndose precisamente a esta carta, también es importante notar cómo, más allá de dar cuenta de lo que en verdad sucedió, Valdivia reconstruye una imagen para Roma (Gaune, 2016: 189), en la cual muestra cómo él y quienes le acompañan dieron todo de sí para conseguir evangelizar los indios en Chile. De tal manera, la promesa es un acto tanto religioso como político por parte del sacerdote, y el que efectivamente termine cumpliéndola sería gracias a que la promesa escrita cumplió su objetivo como refuerzo de su idea original de evangelizar.

De tal manera, la principal preocupación de Valdivia al llegar al territorio sería el trabajo con los indígenas y la expansión del catolicismo, lo que es notorio al comparar las cartas enviadas por Piñas y Valdivia a su llegada a Chile. Mientras que Piñas, como encargado de la misión, se referiría a sus relaciones con el Cabildo y cómo se insertó la orden a su llegada, por su parte Valdivia se refería a sus progresos con los indígenas del territorio:

"Mientras el Padre Rector andava occupado en asentar las cosas de nuestra casa y dar a conocer a la ciudad con obras y sanctas palabras a la Compañía, nosotros, descuidados de todo eso, nos dimos a la 
lengua, la qual comenzamos de propósito un día después de Pascua Ressureccion, y hemos aprovechado en ella y con ella a los indios y edificado a este pueblo. Con los principios que allá aprendí, a los trece días comencé a confessar y a los veinte y ocho prediqué en ella en Sancto Domingo sermón compuesto de mi mano, y de la misma iglesia, el segundo domingo después de Pasqua, comenzamos la doctrina, juntando muchos indios y haciendo una muy solemne processión en que cantamos el Padre Vega y yo." (Egaña, 1970: 466).

A los pocos días de su llegada a Chile, ya se encontraba trabajando para aprender bien la lengua de los indígenas, a la vez que preparando sermones para ellos y confesándolos. Como Valdivia señala, mientras Piñas se hacía cargo de los españoles, él y el padre Gabriel de la Vega se encargaban de los indios, mestizos y negros, intentando de esta manera atraerlos al catolicismo (Kort, 1968: 81). De esta forma, es claro que, si bien estaban preocupados por la fundación del Colegio, no habían olvidado su misión principal, siendo encabezada la tarea misional por Valdivia.

Esto cambia al momento que Piñas debe retirarse al Perú, y Luis de Valdivia se convierte en rector del Colegio. Esta primera etapa del sacerdote, hasta el año 1602 en que debe regresar al Perú, es debatida en torno a su compromiso con la evangelización. Según lo relata Tampe, Valdivia no habría abandonado sus deberes misioneros por su nuevo cargo; al contrario, luego de esto, se habría dirigido al sur del territorio, para continuar con la misión de la orden (2010: 24). Por otra parte, según relata Díaz Blanco, Valdivia no sólo habría dejado de lado su vocación misionera durante este tiempo, sino que se habría dejado llevar por los intereses de la élite santiaguina, incluso apoyando la esclavitud indígena tras la rebelión de 1598, y no volvería a referirse a sus ideales evangélicos hasta su regreso al Perú (2011: 30-31).

Es probable que la pertenencia de Tampe a la Compañía influya en su visión idealizada de Valdivia, sobre todo tratándose de uno de los fundadores de la orden en Chile, pues la misma idea es posible encontrarla en distintos jesuitas que han tratado al personaje de Valdivia. Estos evitan referirse a los seis años en que Valdivia fue rector del Colegio y sólo son mencionados si se hace referencia a su viaje por el sur. Por otra parte, Díaz Blanco (2010), quien ha estudiado a Valdivia y la Guerra Defensiva de manera extensa, presenta una caracterización más realista del personaje, lo cual no resultaría extraño, ya que, al convertirse en el principal encargado de la Compañía en Chile, resulta normal que cambiara su manera de relacionarse con los vecinos y la élite de Santiago, preocupándose de formar buenas relaciones con ellos.

De cualquier manera, más importante que juzgar las intenciones de Valdivia durante ese tiempo, es señalar que, sin duda, la presencia del sacerdote durante este primer periodo fue fundamental para preparar el camino que 
el Colegio y la Compañía seguirían en el territorio durante los siguientes años. Las preocupaciones de Valdivia, entre las que se podrían destacar las mencionadas clases de Arte y la petición de libros para iniciar la biblioteca, ayudaron a instaurar una relación entre la orden y los vecinos. Sobre todo el curso de Arte, que dictó entre 1594 y 1597 (Hanisch, 1962-1963: 31), significó un contacto constante entre la Compañía de Jesús y otras órdenes religiosas (principalmente dominicos, franciscanos y mercedarios) que participaron en las clases, así como de hijos de los vecinos de la ciudad, lo que no sólo posicionó en un lugar preferente al Colegio como centro educacional, pues estos jóvenes, posteriormente, enviarían a sus hijos, creando verdaderos linajes al interior de los colegios, incluso recibiendo, desde la segunda mitad del siglo XVII, distintas becas por parte de las familias de élite ${ }^{8}$; sino que inició un proceso que, en años posteriores, sería constante: la educación jesuita de gran parte de los vecinos.

En 1602 se le ordenó a Luis de Valdivia su regreso al Perú. Esto significó el cambio de rector del Colegio, y marcó un cambio fundamental para la Compañía en Chile y en sus relaciones con los vecinos de Santiago. Como se verá, la Guerra Defensiva postulada por Valdivia, y las complicaciones que las ideas indigenistas trajeron a la orden, fueron definitorias en cómo los sacerdotes debieron convivir con los santiaguinos.

\section{La opinión de los vecinos}

A lo largo de la primera etapa de la Compañía en Chile, existen una serie de testimonios que nos relatan el favor con el que contaba la orden entre algunos de los vecinos de la ciudad. De esta forma, es representativo el ejemplo de Doña Catalina Morales, esposa del General Gaspar de Pulgar (Medina, 1906, 705), quien en 1638 hizo donación a la Compañía:

"de las cassas de mi morada. en que al presente bivo. que sson en esta çiudad. en la plasuela de dicho colejio linde con cassas de doña tereza de carabaxal y en ellas entra. y se conprehende otra cassa mia pequeña asessoria, en las que yo bivo linde calle rreal, en medio con el colejio que nuebamente esta fundado en las cassas que solian ser del capitan francisco de fuensalida y ssobre las unas y otras tan solamente tengo [alensso] quatroçientas y çinquentata pessos de a ocho pertenesientes. a la capellania del señor [obispo] medellin. su rrenta se paga al padre marios rrubio presvitero y tambien hago donaçion de un mil y seteçientos pessos. de a ocho de zensso prinçipal que me tocan.

8 La "Beca Ovalle" fundada en 1650 por el padre Alonso Ovalle, la "Beca Lecaros" y la "Beca Aguirre", ambas creadas en 1745, y la "Beca Roco de Carvajal", creada en 1700. 
de la chacara y viña que bendi a Leonardo [Nequel] y de duçientos pesos de Zensso que tengo ssobre las cassas que bendi yo y el dicho mi marido a gaspar albares sson en la cañada y de seis esclavos nombrados _ graçia : ygnaaçio de Jesus: francisco jabier. ana de morales y maria de la asunssion Juan de dios _ y de todos los demas vienes que tengo y tubiere despues de mi muerte hasi muebles como rrayses y de la rrenta que tengo en los almojarifasgos. de la çiudad, de çivilla con declarassion que el usufruto de los dichos vienes [lo e de gossar] yo por todos los dias de mi vida y despues de mi muerte a de entrar en ellos. el dicho colesio [sic] de la compañia de jesus y para que los aya [e gosse] como suya...". ${ }^{9}$

La mencionada, sin dudas, puede ser considerada como una donación impresionante. No sólo le entrega un terreno cercano a su colegio, por lo que se puede asumir que su valor no era menor en términos monetarios y simbólicos, sino también una renta, una viña, esclavos, etc. Declara a la Compañía como sus herederos "por cuanto no me quedaron hijos ningunos, del dicho mi marido ni tengo herederos forsosos..." ${ }^{10}$, entregándoles todos sus bienes, básicamente los vestigios de su vida, a la orden, para que ésta los disponga como le parezca pertinente. Como justificación para tal acto, declara que:

"...en vida del dicho mi marido y despues de su muerte los padres del colejio de la compañia de jesus desta dicha ciudad siempre an tenido y tienen particular cuydado de acudir a las cossas tocantes a mi alma y del dicho mi marido y a otras nesesarias de mi salud sin ynteres alguno por cuya rrazon y por otras caussas justtas que a ello me mueben dignas de buena correspondenzia y que estoy sierta dichos padres despues de mi muerte la continuaran con el afecto y [obras] como hasta aqui lo an fecho." 11.

De la misma forma, Pedro del Portillo, quien ocupó una serie de importantes cargos durante su vida (Medina, 1906, 698), donaría todos sus bienes a la Compañía tras su muerte, declarando que:

"siempre a ssido y es afecto a las cosas de la compañia de hessus y de Pressente ha mes de agora a receuido muchas y buenas obras de los Padres de [dicha] compañia de jesus del collegio de la dicha compañia de jesus fundado en esta dicha ciudad. Y para lo de adelante espera receuir las cifras de remuneracion y toda buena correspondencia y Por que esta cierto y en ello no pone en de [duda] que despues de su

9 ANHCh, Fondo Jesuitas de Chile, Vol. 124, f. 139v-140.

10 ANHCh, Fondo Jesuitas de Chile, Vol. 124, f. 139.

11 ANHCh, Fondo Jesuitas de Chile, Vol. 124, f. 139 
muerte y [...] la que se ofresca y de Pressente de los Padres acudiran y an de acudir a las cosas de su alma en vida y muerte hacerse los sufragios que a costumbran hacer a los [vienechores] de la compañia de jessus; a [de su dicho colegio] y de su libre y de espontanea voluntad para gosar del Reyno del cielo...".12

En este caso, Portillo señala de manera clara las razones para donar a la Compañía, fijando la mirada en que la orden se encargue de su alma tras su muerte y, así, poder llegar al cielo. Esto no es raro, por el contrario, las donaciones a alguna orden eran normalmente acompañadas por peticiones de ese tipo. Aun así, la petición sirve para reafirmar la idea del lugar que ocupa la Compañía en el espacio santiaguino y en su contacto con los vecinos, pues también remarca la importancia que ha tenido la orden mucho antes de su muerte, con sus obras y trabajos, así como lo señalaba anteriormente doña Catalina Morales. Se resalta la acción de la Compañía en vida, sus obras humanas y cómo ha ayudado al entorno del donante, no sólo de manera espiritual, sino también fáctica.

Por otra parte, desde inicios del siglo XVII se pueden observar algunos ejemplos del lugar que comienza a ocupar la orden en Santiago. Así por ejemplo, en el Cabildo de 24 de enero de 1604 se declara: "En este cabildo se trató como para hacer el reloj de esta ciudad que se puso en el Colegio de la Compañía de Jesús se tomó una viga á María Hernández, viuda, para la dicha obra, muy grande, que valía doce pesos: mandan se le dé libramiento para diez pesos para el mayordomo" (Medina, 1900, 82). Un reloj no es un objeto cualquiera, sobre todo durante la colonia. Pasar de una percepción intuitiva del tiempo -basada en la demora de los rezos, el número de campanadas (Valenzuela, 1992: 234 - 239), la posición del sol o la velocidad de un caballo- se pasa a una medición estable y constante, separando el día en intervalos claros e ineludibles, y bajo los cuales ahora la ciudad se regiría. Colocar tal aparato en el Colegio jesuita significaba que el resto de los habitantes de la ciudad tendría que observar su edificio cada vez que necesitaran ver qué hora era, lo cual, es de suponer, puso a la orden en medio de las necesidades locales (Valenzuela, 1992, 242), y con una responsabilidad que las otras órdenes no tenían.

Junto con esto, otro testimonio nos llega desde la Carta Anua de 1630 del padre Sobrino, quien relata que, por ser muy pocos los jesuitas en Santiago, tiene problemas: "en acudir a las de nra. iglesia Los dias festivos y de jubileos, por[que] es la mas frequentada de esta siudad y las personas principales en

12 ANHCh, Fondo Real Audiencia, Vol. 2114, f. 108. 
particular mujeres se confiessan en ella poniendo por dicha confessar sus hijas en la compañia"13. Y así, sobre los mismos jubileos, explica que:

"recibio bien en el pueblo mostrando el affecto y estima que tienen de la compa, ganaron casi todos los de el el [sic] santo Jubileo. Con tan buen principio se començo La quaresma con lucidissimos auditorios Llenandose Los domingos en la tarde nuestra iglesia, en q aueses se contauan sobre 700 personas Las mas Lucidas y principales del pueblo". ${ }^{14}$

En la carta se muestra una Compañía apreciada por la ciudad que atrae a algunos importantes vecinos, así como a muchas de las mujeres que viven en Santiago. Resalta de manera especial cómo logra atraer a grandes grupos de personas y cómo son aclamados y solicitados por ellos.

Ahora bien, como ya se ha explicado anteriormente, la carta, al pertenecer a un jesuita, no es totalmente confiable para los resultados que aquí se buscan. Pero es posible comparar esto con lo que, en 1640, escribía el Obispo de Santiago Gaspar de Villarroel sobre la Compañía de Jesús, y:

"...la grande necesidad que de los dichos Religiosos hay en este Reyno, y dadome relacion de los que precisamente son menester para los Colegios y casas de su cargo, juzgo que esta ajustada con lo inescusable; y para que a Vuestra. Magestad le conste con toda certeza el estado de la materia, la envio con esta autentica. Y ha entrado tan mal la Christiandad en los yndios deste Reyno, que me juzgara por un obispo infeliz, a no tener en el esta Santa Compañia de Jhesus. Son en Chile pobrisimos estos Religiosos, excelentes letrados, y muy virtuosos; inclinanse pocos en esta tierra a entrar en la compañia, por lo mucho que travaja...". 15

El obispo Villarroel, como vecino de la ciudad, avalaba la visión positiva sobre la Compañía, lo cual es aún más relevante al considerar su pertenencia a otra orden, la de San Agustín. Asimismo, no es sólo manifestar que los jesuitas sean una orden "positiva" para el territorio, sino que resalta el esfuerzo de estos, así como las dificultades que deben sobrellevar para cumplir sus tareas; los cataloga como "letrados" y "virtuosos", caracterizándoles una vez más como una orden preocupada por la educación, y luego señala lo "mucho que trabaja" la Compañía en el territorio. Claramente, se crea una imagen de la orden enfocada en su rol activo hacia la sociedad, ya sea en Santiago

13 ANHCh, Fondo Jesuitas de Chile, Vol. 93, f. 3v.

14 ANHCh, Fondo Jesuitas de Chile, Vol. 93, f. 3v.

15 Archivo del Arzobispado de Santiago (AAS), Fondo Gobierno, Vol. 25, f. 72-73. 
directamente con los vecinos, como con la evangelización de indígenas. A la vez, por el Cabildo de Santiago se tienen algunos testimonios del papel que desempeña la Compañía. Así, por ejemplo, en el Cabildo de 25 de febrero de 1623, se discute sobre la construcción del puente del río Maipo, el cual se le encargaría al cantero Iñigo de Arana y al hermano Francisco Lázaro, artífice de la Compañía, quienes propusieron un puente de ladrillo, que sería más barato y resistente que el de madera que se tenía planeado. Se reconoce la valía del hermano Lázaro, así como su experticia en el tema a tratar, confiándole la construcción de tan importante obra (Medina, 1902: 121). Posteriormente, en febrero de 1638, se presenta una nota ante la deuda que el Cabildo mantiene con algunos vecinos que ayudaron a la compra de arcabuces $y$, entre ellos, se encuentra el Colegio de la Compañía de Jesús (Medina, 1905: 280). Asimismo, en enero de 1645 se solicita al padre Baltasar Ruiz, jesuita, predique en la capilla de la cárcel durante la cuaresma (Medina, 1906: 6).

Todas estas acciones, separadas por los años, no son más que una muestra de lo que se ha mencionado desde el principio. La Compañía de Jesús se inserta en el panorama santiaguino de manera activa, ayudando con puentes, prestando dinero al Cabildo y sirviendo en las necesidades públicas en general. Se presenta, y se precia, como cercana a las necesidades vecinales, lo cual se observa en las actas del Cabildo y en la opinión general de los vecinos.

De tal forma, se va armando una opinión bastante clara de la Compañía. Los distintos testimonios, así como la acción de la misma en sus distintos ámbitos, la presentan como una orden que se interesa en interactuar con la vecindad. Buscan ganar el favor de los vecinos, rezando por sus almas o visitándolos en su enfermedad, así como de aquellos que no gozan de tal condición, como, por ejemplo, visitando esclavos negros para su evangelización.

Es posible que, dentro del periodo estudiado, una de las mayores pruebas del favor con que la Compañía gozaba en Santiago se vea reflejado en la muerte del padre Juan Romero, antiguo rector del Colegio. El padre Sobrino lo relata así:

"Echa señal el primer doble no es posible declarar el gran sentimiento del pueblo La gente principal que acudio a nuestra porteria no hablando todos aquellos 8 dias de otra cosa que de la heroica santidad del Padre Aviase de celebrar La fiesta de pasqua el siguiente dia en La cathedral y mando el Señor reverendissimo se dilatasse para otro dia, el predicador era un canonigo desta iglesia mui buen predicador, y dando La causa de aver dilatado La fiesta dixo aver sido traça del cielo para honrrar Christo Señor nuestro a quien tanto se le auia honrrado en esta vida, y prosiguio haciendo un gran elogio de las virtudes y santidad del Padre A las 8 acudio tan gran numero de gente a nuestra casa y iglesia que no nos podiamos menear, Los señores oydores 
vestidos de Luto, y lo principal del pueblo, entranbos cavildos, hiço el officio su antiguo amigo el Señor obispo don francisco salsedo, y començando en la capilla a cantar el responso sollosava tanto y derramava tantas lagrimas que no fue posible proseguir cantando, acompañavanle con lagrimas los oydores y de mas gente sacaronle en ombros los principales...". ${ }^{16}$

Quizás, en el periodo tratado, sea una de las demostraciones públicas más importantes en favor de la orden. La despedida al padre Romero no sólo congregaría a un gran número de asistentes, sino que algunos de los vecinos más influyentes estarían presentes en ella, como lo es el obispo Francisco Salcedo, quien había llevado una importante carrera eclesiástica en América (Medina, 1906: 795). Los obispos, ya fuese Salcedo o Villarroel, representaban la máxima autoridad eclesiástica, por lo que su apoyo sin duda influía favorablemente en la Compañía. Junto con eso, el que se presentaran los oidores y el Cabildo, las instituciones civiles más importantes, da muestra asimismo de la aceptación que el padre Romero, y por implicancia la orden, tenían con la esfera social en Santiago.

Así, para la década del 1640 nos encontramos con una Compañía de Jesús que, sí bien nos resulta imposible siquiera sugerir que sea la orden más importante, si goza de un favor generalizado entre los vecinos y las principales instituciones civiles y eclesiásticas, dejando a la Compañía en una posición bastante cómoda frente a la sociedad. La interacción entre los vecinos y los jesuitas sería una constante relación de altos y bajos. En este capítulo se revisaron principalmente los aspectos positivos de dicha relación, y cómo los jesuitas eran alabados y respetados por muchos de los vecinos de la ciudad, así como el lugar de importancia que tenía el Colegio Máximo dentro de la comunidad santiaguina. La presencia terrenal que la Compañía mostraba en la ciudad (en educación, medicina y economía) los mantenía unidos a los vecinos y a sus necesidades, convirtiéndose el Colegio entonces en un centro importante dentro de la comunidad gracias a los que éste podía entregarle. Ahora bien, toda relación tiene dos caras. A continuación, se verá el aspecto negativo de la interacción entre vecinos y jesuitas.

\section{El punto de inflexión: ¿qué significó la Guerra Defensiva en Santiago?}

Tras el llamado Desastre de Curalaba, en 1598, se perdieron las siete ciudades al sur del río Biobío, lo que significó un duro golpe para los españoles

16 ANHCh, Fondo Jesuitas de Chile, Vol. 93, f. 7-7v. 
en el territorio. Asimismo, la muerte del gobernador Martín García Óñez de Loyola, el segundo gobernador muerto por los indígenas, evidenciaba que la zona de Arauco no sólo no estaba controlada, sino que era un posible peligro para las otras ciudades hispanas en Chile.

Para poder contrarrestar esto, se propusieron distintos planes que, por una parte, atrajeran más soldados a las tierras del sur, y por otra redujeran cada vez más el número de indios rebeldes. La esclavitud indígena aparecía como una respuesta satisfactoria para todas las partes, pues por una parte entregaba una recompensa económica a los soldados y, por otra, ponía a los indios rebeldes bajo el cuidado de español que, en teoría, lo educaría como un buen cristiano. Así, por ejemplo, en 1610 se argumenta que:

"Considerando la necesidad en questá este reino por la poca gente de guerra que hay en ella para la que es menester y particularmente en tiempo de la muerte del señor gobernador Alonso García Ramón, que santa gloria haya, con las muertes de los cuales los indios de guerra destas provincias han causado en ellas grandes alteraciones y fecho grandes daños, (...) Considerando que les podría ser de alguna ocasión para con voluntad servir á S.M. en la ocasión presente el pillaje de los indios y muchachos que se cogiesen en la guerra, dándolos por esclavos en conformidad de la nueva cédula proveída por S.M., y porque Su Señoría está determinado de publicarla y ejecutarla luego que enhorabuena sea llegado á la ciudad de la Concepción, declarando por esclavos á todos los dichos indios que se cogieren en la guerra después del tiempo de la dicha publicación" (Medina, 1901: 188-189).

El plan era claramente atractivo para los soldados españoles. A diferencia de la Encomienda de Indios, la esclavitud significaba un servicio personal directo, no una tributación indirecta y, por tanto, era mucho más rentable, y se encontraba en menos peligro de acusaciones de abuso contra los indígenas. Junto con esto, la idea general parecía apuntar a que la esclavitud y el castigo resultarían las únicas maneras de adoctrinar a los indios al sur del Biobío. Es en este punto en que reaparece Luis de Valdivia.

El jesuita, que desde el término de su rectorado en el Colegio Máximo se había trasladado a Lima, comenzó a plantear la posibilidad de que se efectuara otro tipo de conquista. Ya desde 1604 proponía en sus cartas que el abuso y la sobrecarga de trabajo contra los indios sólo los alejaría de la religión (Díaz, 2011: 85-99). Por esto, su plan proponía lo contrario. En primer lugar, llamaba a terminar con cualquier tipo de servicio personal de parte de los indígenas. Posteriormente, propuso que la conquista no debía realizarse por medio de las armas, sino por un avance pacífico encargado a los misioneros, quienes convertirían de esta forma a los bárbaros del sur, causando menos rechazo que los soldados y sus armas. 
La estrategia de Valdivia se insertaba en un momento en que, a nivel global, los jesuitas comenzaron a movilizarse e implantar sus ideas misionales en el territorio español. De esta forma, por ejemplo, se encuentran las misiones del Paraguay, donde se crearon una serie de reductos autónomos de cualquier villa española, en los que los jesuitas se encargarían de adoctrinar a los indios del territorio, protegiéndolos y educándolos. De la misma manera, Mateo Ricci (Ginzburg, 2014: 307-309) se había dado a la tarea de convertir a China al cristianismo, lo que le significó aprender su idioma y mezclarse con las élites chinas, al punto de utilizar conocimientos chinos para la creación de sus propios conocimientos, muestra de lo cual es el uso de sabios chinos en la elaboración de su mapa mundi (Roberto Chauca, 2016: 23-24). De tal forma, las lógicas seguidas por Valdivia no se desviaban de los planes globales de la orden, dando mayor fuerza a la función activa del misionero, y utilizando los contactos que habían ya logrado con las élites locales para cumplir esta tarea.

Valdivia, desde su llegada al territorio chileno con el primer grupo desde Lima, se había preocupado tanto de aprender el idioma como de evangelizar a los indios en guerra. Por tanto, su interés no estaba centrado en la conquista económica o territorial, sino de las almas de estos. Ante tal perspectiva, una guerra que permitiera un menor número de víctimas era mucho más útil que la guerra a "sangre y fuego" española, pensada para conseguir prisioneros y recompensas.

Con esto en mente, Valdivia consiguió, por parte del General Claudio Acquaviva, un poder especial para evitar las órdenes del provincial Diego de Torres y encargarse personalmente de los asuntos de la Guerra Defensiva, la cual sería aprobada por el Rey en 1610, y puesta en práctica en 1612. Sobre la guerra misma no interesa para este estudio una mayor explicación, pues el enfoque no es en esta ocasión el desarrollo de la guerra, sino, cómo ésta fue percibida y recibida por los habitantes de Santiago, tan alejados de ella, pero aun así afectados.

En el Cabildo de 24 de septiembre de 1610, se inició la sesión discutiendo sobre un tema que, de inmediato, alarmó a los miembros cabildantes. Según las noticias que les habían llegado desde España, el padre Valdivia se encontraba en conversaciones con el Rey y el Consejo Real para que se eliminara el Real Situado y que la guerra se pagara con los medios propios de la región. Ante esto argumentaban que:

"si viniese en efeto sería total destruición é ruina deste reino; para lo cual se ha consultado y acordado en este cabildo que, vista las cartas que Despaña vienen en esta razón, se dé aviso al señor Gobernador, á las ciudades de la Concepción y San Bartolomé, para que den sus pareceres, y en esta conformidad se procure reparar tan grande daño, las cuales diligencias y cartas se cometen al general 
don Pedro Lisperguer que las escriba y avise, y en el ínter asimismo en esta ciudad se dé parte deste tratado al señor oidor Joán Cajal, persona á quien incumben las cosas de la guerra, para que tome acuerdo de los capitanes y los de la ciudad y de hábito" (Medina, 1901: 199-200).

Un par de meses después, en febrero de 1611, se llevó a cabo una reunión en el Cabildo para discutir la prohibición del servicio personal indígena:

"se juntaron en las casas de cabildo, (...), los prelados de los conventos de San Domingo y San Francisco y San Agustín y de la Merced y otros religiosos de las dichas órdenes y algunos caballeros desta ciudad que han sido deste Cabildo y otras personas, que á todos estando juntos y congregados, (...), ya sabían y entendían la instancia que se hacía y lo que se pretendía por el señor fiscal de Su Majestad que la Real Audiencia desta ciudad alzase y quitase el servicio personal, dando las causas y razones que para ello tiene; y que en este caso todos los que presentes estaban, como personas de tanta ispiriencia, noticia y conocimiento que dello tienen, se trate y confiera lo que más convenga al servicio de Dios, nuestro señor, y de Su Majestad Real y bien de los indios, por aumento y firmemento (sic) dellos y que entre todos los questaban presentes tratasen y confiriesen lo que en esta razón más convenga hacer, pedir y suplicar á Su Majestad y á la Real Audiencia desta ciudad" (Medina, 1901: 223-224).

Lo primero que se debe notar es quiénes fueron convocados a la sesión. Claramente, hay una orden que no aparece en el listado. La Compañía de Jesús habría sido excluida de esta petición que se realizaba, lo que se explica por obvias razones, siendo un jesuita quien aboga por el fin de dicho servicio. Aun así, cuando se considera que los invitados eran capitanes, caballeros, prelados, etcétera, haber sido excluidos no debió ser algo menor. Básicamente, se llamó a las principales personalidades de la ciudad a dar su apoyo a la continuación del servicio personal y, entre ellas, no se consideró a la orden jesuita.

Junto con eso, se menciona que todos los presentes eran gente de experiencia y conocimiento acerca de lo mejor para el Rey y para los indígenas. Al no invitar a la Compañía a esta reunión, no sólo estaban excluyéndolos de un proceso eminentemente vecinal, sino también negando su capacidad como misioneros, pues lo que ellos pudieran saber al respecto, no convenía para los intereses del Cabildo. Continuaba el acta:

"...y habiéndose tratado y razonado, y unos y otros dado su parecer, quedó resuelto y acordado que por parte deste Cabildo y de personas desta ciudad se suplique y pida á la Real Audiencia della, se suspenda 
la determinación y resolución de lo pedido por parte del dicho señor fiscal y no se trate de sus libertades hasta tanto que de Su Excelencia del señor Virrey del Pirú, á quien se entiende está cometido este particular por Su Majestad Real, ordene otra cosa; y asimismo se escriba y pida en nombre desta ciudad á su excelencia del señor Virrey del Pirú, advirtiendo y haciendo relación lo que convenga en este caso y lo que más necesario sea en servicio de Su Majestad" (Medina, 1901: 223-224).

Finalmente, la resolución que el Cabildo envía a nombre del "Cabildo y de personas desta ciudad" crea una respuesta vecinal contra lo que se está planeando, y contra las intenciones de Valdivia. La asociación del jesuita con su orden significó una primera exclusión de la Compañía en temas referentes a la ciudad y sus intereses. La primera, pero no la última.

Para octubre de 1611 la preocupación por la implementación del plan de Valdivia, y el fin del servicio personal, llevó a que el Cabildo enviara un representante a Lima para defender la postura vecinal frente al virrey:

"elegimos y nombramos por nuestro procurador en este particular al muy reverendo padre fray Jerónimo de Hinojosa, de la orden de Predicadores, por la mucha noticia y experiencia que tiene de las cosas deste reino y estado de la guerra, al cual le damos y otorgamos nuestro poder cumplido, con libre y general administración, para que en nuestro nombre y desta dicha Ciudad se muestre parte y parezca ante el Exmo. señor Virrey del Pirú ante quien y á donde á nuestro derecho convenga, y pida y suplique á Se Excelencia le oiga y admita sus razones y propusiciones que en contradición ó aprobación de lo que se intentare en esta materia hubiere, y lo que fuere en favor desta ciudad y reino apruebe y lo en contrario en su perjuicio y daño contradiga, y que Su Excelencia se sirva suspender el efeto y resolucion dello" (Medina, 1901: 287).

Se va aquí configurando el espacio donde radica la queja principal y la simbólica exclusión de la Compañía. Junto con el claro conflicto de intereses entre lo propuesto por Valdivia y por el Cabildo, existe también la omisión que se hace de los vecinos a la hora de tomar la decisión de terminar con el servicio personal. Constantemente se haría mención de que la decisión debe convenir al reino y a la ciudad y, por eso, debe protestarse la decisión guiada por Valdivia. Es posible que excluir a la Compañía en un comienzo respondiera también a cierta respuesta ante la exclusión que los vecinos sufrieron de manera general por el padre Valdivia al proponer su plan al Rey.

Junto con esto, que podría considerarse una medida "legal" de protesta por parte del Cabildo, hay registro de una segunda estrategia que se estaría 
gestando en el territorio del Biobío. El 11 de enero de 1613, el procurador general Pedro Lisperguer presentó ante el cabildo una carta del provincial de la Compañía de Jesús, Diego de Torres, en la cual se reclama el que "algunas personas habían escripto á los indios de guerra de los de esta ciudad, diciéndoles que las paces que el padre Luis de Valdivia les ofrecía eran falsas" (Medina, 1901: 374). Ante esto, se le pide a Lisperguer encontrar al responsable de esto y solucionar el inconveniente (Medina, 1901: 375). El problema continuaba dos meses después, recibiéndose carta del padre Valdivia en 26 de marzo de ese año, en la que se repetía el problema de encontrar "satisfación de las calunias que se le imputaron á esta ciudad sobre haber escripto para los indios de guerra que no diesen ni aceptasen las paces que se les ofrecían" (Medina, 1901: 399).

La situación no habría pasado a mayores, al menos en Santiago, pero demuestra la profundidad del problema que Valdivia significaba para los encomenderos españoles y vecinos de Santiago. Más allá de interesar si de verdad fue alguno de estos vecinos el que inicio el rumor, o si el rumor realmente existió, lo importante es que demuestra una clara tensión entre ambas partes. Valdivia, preocupado de llevar a cabo el plan de la Guerra Defensiva, no pudo permitir que los encomenderos, temerosos de perder sus privilegios, difundiesen calumnias malintencionadas en contra de su trato con el Rey. Asimismo, los vecinos se encontraban divididos entre la obediencia que deben rendirle a las órdenes reales y sus intereses económicos; de tal forma, el rumor y la calumnia servirían como una respuesta subterránea de protesta contra las órdenes reales, al no poder identificar a un responsable de esta, pero sí su intencionalidad.

Todos estos problemas se acrecentaban al considerar que a fines de diciembre del año 1612 ocurrió el asesinato de tres sacerdotes jesuitas a manos del cacique Anganamón (Díaz, 2010: 236-237). Tal evento traería críticas para el programa que Valdivia trataba de imponer y, sobre todo, a la real capacidad de los sacerdotes para continuar esta guerra. Así, en Cabildo del 16 de enero de 1613, se expresa que los indios:

"...no habiendo querido aceptar las paces que se les han ofrecido, antes, contraviniendo á algunas falsas que han ofrecido, mataron á los padres de la Compañía de Jesús que los iban á predicar, para que en nombre de este Cabildo y ciudad pueda parecer ante el señor visorrey de el Perú, don Juan de Mendoza y Luna, marqués de Montesclaros, y adonde y ante quien al derecho de esta ciudad y Cabildo convenga, como á quien está remitido las cosas de el estado de la guerra de este en ella está puesta y dar licencia al señor presidente y gobernador de este reino, Alonso de Ribera, para que pueda hacer la dicha guerra á los dichos indios, á fuego y sangre, castigándolos como convenga, y para que disponga en las cosas de ella como quien las tiene presente; 
y asimismo que sea servido de socorrernos con todos los soldados que fuere servido de suspender al presente la orden que tiene dada para que se alce el servicio personal de esta dicha ciudad hasta que Su Majestad sea servido de socorrernos con los negros que le tenemos pedido para el sustento de los vecinos y moradores de esta ciudad, ó envíe nueva orden, y que cese la visita particular cometida al padre Luis de Valdivia y á sus sostitutos de la Compañía de Jesús..." (Medina, 1901: 376-377).

El "Martirio de Elicura", como se conocería la tragedia, serviría como uno de los principales argumentos para defender la guerra ofensiva contra los indios (Díaz, 2010: 238 - 239), desechando las ideas de Valdivia. Asimismo, se utilizaría para pedir el regreso del servicio personal, como medio para atraer más soldados y así regresar a la antigua práctica. Es curioso que se pida al Rey que envíe esclavos negros para suplir a los indios y que mientras no existan estos esclavos, el servicio personal se reactive, pues así se confirma que el principal inconveniente es referido a este punto, y que, de cierta forma, se culpa al Rey de la falta de servidores en el reino, pues le ha permitido a Valdivia llevar a cabo su plan, sin tener los medios para suplir a los indios.

Con la Guerra Defensiva ya en funcionamiento, la molestia de los vecinos hacia la Compañía aumentó. El padre Juan Pastor escribe:

"Recevi la de 24 de Agosto de 1614 con harta pena de la nueva de que alla estan los ministerios de la Compañía tan caidos como VR. escrive, por ocasion del servicio personal, y por el arbitrio y negocio de que el P. Valdivia fue encargado por orden de su Magestad y de su Consejo. Y pues lo que en todo se ha pretendido fue la mayor gloria de Dios y bien spiritual de esos naturales, espero que su divina magestad sera servido que se aplaque la tempestad ayudando a ello las buenas partes del nuevo provincial a quien podra V.R. informar de la falta de suavidad que dize se nota en el Rector desse Colegio, porque no dexara de irle a la mano para que proceda con la devida suevidad y paterno amor" (Morales, 2005: 127).

Ese mismo año, el padre Romero escribía:

"Mucha pena me dio lo contenido en la de IV.R./ de 29. de agosto de 1614, assi por lo que los nuestros padecian en essa ciudad; como por que no siendo bien vistos del pueblo, es cosa clara que los ministerios de proximos iran en caida. Verdad es que siendo como es negocio de Dios, devese acudir a su divina magestad para que sirva poner su mano y remediarlo como fuere para su gloria y provecho spiritual de las almas, que es lo que en todas nuestras actiones se deve pretender. Alla ternan ua el nuevo provincial, cuya direction y buenas partes ayudaran para ir ganando Vas/voluntades de los que se an mostrado 
aversos; y de nuestra parte hara que se proceda con mayor tiento en las cosas, para que por falta desto no se impidan bienes mayores con daño de las almas" (Morales, 2005: 128).

En ambas cartas es evidente que la orden está pasando por problemas en Santiago. La Guerra Defensiva en el sur les estaba costando sus gracias en la capital, y es que debido a las políticas que serán planteadas para Chile por parte del Rey y del provincial de Lima, el padre Luis de Valdivia se convertirá en una suerte de provincial de Chile, quien sólo debía responder ante Roma y España (Díaz, 2010: 214 - 215). De tal forma, el resto de los jesuitas en Chile debían seguir sus directrices y apoyar su plan de guerra, por lo que ahora era un blanco fácil para las críticas que los vecinos tenían hacia Valdivia y su estrategia. Ante esto se lamentan los sacerdotes que, desde Santiago, debían responder ante los vecinos. Y es que no debió ser nada fácil estar en la posición del padre Romero, quien debía, por una parte administrar el Colegio Máximo, del que era rector $y$, por otra, intentar mantener buenas relaciones con la ciudadanía; mientras que el plan de Valdivia se llevaba importantes recursos del Colegio, sobre todo profesores/misioneros, y llamaba a un constante rencor por parte de los vecinos.

Sobre este punto, Gaune plantea que existió un discurso antijesuita externo descentrado, el cual no atacaría a la Compañía en su conjunto, sino que se enfocaría en criticar principalmente a Valdivia, pues sería él quien habría excedido sus atribuciones, a vista de los afectados por la política de guerra (2016: 283, 390). Aun así, es importante señalar que, si bien es cierto que gran parte de las críticas iban hacia Luis de Valdivia (incluyendo críticas desde la misma Compañía), el sentimiento antijesuita afectó igualmente a la orden en conjunto, al menos durante el tiempo que duró la Guerra Defensiva. Muestra de ello son las citadas cartas de los padre Romero y Pastor. En tal caso, aunque existe una separación discursiva en la crítica, entre el Valdivia político, quien es perjudicial para los intereses vecinales, y el Valdivia jesuita, representante de la orden, de todas maneras los rencores hacia él se traspasarían a su grupo, y la Compañía se vería afectada por esto.

Ante la crítica situación de los jesuitas con la ciudad, se buscó una manera de mantener las buenas relaciones dentro de lo posible. Así, por ejemplo, se encuentra la carta de 1614 del provincial Pedro de Oñate:

"Hizo V.R. muy bien de consultar en Lima Vas cosas/ pertenecientes al $\{\sim\}$ servicio personal, y negocios que estan a cargo del P. Valdivia por que con la noticia que ira tomando podra ayudarse del buen parecer de aquellos Padres segun viere ser mas expediente adulzando todo lo mas que sea possible, sin contravenir al orden que de aca llevo, de su Magestad y de su Consejo. Deve tambien procurar que el dicho Padre se reconcilie con el Governador de Chile y por dezillo en una palabra lo 
que nuestro P. Claudio escrivio a V.R. en 28 de enero de 1614 acerca de como se a de aver con el dicho P. Valdivia" (Morales, 2005: 128).

En ella, se plantean algunas pautas sobre cómo reconciliarse con la ciudadanía, y sobre todo con el gobernador. Se espera que, una vez la Guerra Defensiva comience a dar frutos, todos entenderían su utilidad. Así, es posible observar la importancia que, para la Compañía, tiene mantener sus contactos con la ciudad. Es importante mantenerse en ella y mantener su posición a ojos de los vecinos.

Para 1618 la situación no había mejorado al respecto. En una carta del padre Romero se expone que:

"ay en la frequencia de los ministerios de proximos, que cierto me tenia esso con cuidado aviendo sabido la causa de averse los vezinos dessa ciudad, retirado tanto del trato con los nuestros. Y pues abran echado de ver que solo vamos en busca de sus almas para llevarlas al que las redimio, espero que proseguiran en acudir a nuestra iglesia y aprovecharse, ayudando para ello la religion de V.R. Ya las missiones desse Reyno estan a cargo del P. provincial como lo restante desa Provincia y assi descansara el buen P. Luis de Valdivia que tan exemplar y loablemente ha trabajado"

Los vecinos se han "retirado del trato" con la Compañía de Jesús, y al alejarse de ella, han complicado la misión que debe cumplir. Una muestra evidente de ese alejamiento es el acta de Cabildo del 2 de abril de 1618, en que se le permite a Joán de Oropesa a "...que ponga escuela de enseñar á leer y escrebir á los hijos de los vecinos de esta ciudad" (Medina, 1901: 247). A Oropesa se le había negado anteriormente la escuela en favor de la Compañía (Medina, 1901: 152), pero ahora, sólo 2 años después, se le daba permiso para educar a los hijos de vecinos.

Ante esto, se tiene un caso muy particular de incomprensión entre la Compañía y los vecinos de Santiago. Para los jesuitas, como se ha explicado antes, ser misionero y ser educador eran dos caras de la misma moneda. Ser profesor o misionero eran maneras de llegar a Dios y difundir su palabra, por lo que el jesuita satisfacía su misión ya fuera trabajando en el Colegio o en el Biobío. Pero, para los vecinos de Santiago esto no funcionaba así. La sociedad santiaguina diferencia radicalmente ambas tareas, y mientras premiaba una -la educación jesuita no sólo era importante en el reino, sino que, como se ha visto, resultaba indispensable para los vecinos de Santiago- castigaba la otra. La vocación misionera jesuita no calzaba con los intereses vecinales, y con ello se quebraba la regla principal para mantener las buenas relaciones: ser útil. Pues finalmente todo se reducía a eso. Mientras que el jesuita profesor era útil, el jesuita misionero no. En ningún momento se entendió que ambos jesuitas eran uno solo. 
De esta forma, al entregarle el derecho para abrir escuelas a otro vecino, y al alejarse de la Compañía, los vecinos "castigaban" a los jesuitas profesores, como representantes de su orden, privándolos de la capacidad de "misionar" a cabalidad.

Pero, para 1621, las cosas comenzarían a mejorar para la Compañía. Sin duda, la partida del padre Valdivia hacia España en 1619 ayudaría a calmar las tensiones entre españoles y jesuitas. Sin el principal exponente de la Guerra Defensiva, los otros jesuitas no se encontraban especialmente entusiasmados con encargarse de ella. Así lo presenta el padre Romero en una carta de 1621:

"Huelgome mucho del grande serviçio que ha hecho a nuestro Señor el Padre \{89r\} Luis de Valdivia en ese Reyno, aunque aya sido a costa de tantas persecuciones como se an padeçido; pero pues emos experimentado los graves inconvenientes que se siguen de entremeternos en los arbitrios de guerra defensiva, y ordenes de su Magestad importa en todo caso que no se trate mas de esa materia. Sino dejarla a los ministros del Rey y nosotros $\{\sim\}$ atendamos solamente a nuestros ministerios, que esto es lo que conviene a la mayor gloria de nuestro Señor, a la paz y quietud de esa Provincia; y me consuelo que VR este tan puesto en esto; y me persuado que con su mucha religion y prudencia avra aplacado a los que estavan sentidos de la Compañia y ganado las voluntades de los menos affectos en orden de hazer el fruto en sus almas que deseamos. Guarde nuestro Señor a VR en cuyos santos sacrificios etta" (Morales, 2005: 229-230).

Si bien reconoce el servicio del padre Valdivia, afirma que ahora le compete a la autoridad real continuar con la estrategia, y decidir qué será en el futuro. Por el contrario, llama a encargarse de sus ministerios y así intentar recuperar las voluntades de los vecinos, perdidas durante los años anteriores. Esto lo ratificará el año siguiente el padre Sobrino:

"Ya tenía yo notiçia del inconveniente que se seguiria si bolviesse a ese Reyno el Padre Luis de Valdivia, y para prevenirlo e dado liçençia al dicho Padre que se que en Hespaña; y encargo al Padre Provinçial $\{4 \mathrm{v}\}$ de esa Provincia que ninguno de los nuestros se entremeta en el arbitrio de la guerra defensiva, sino solamente en lo que es proprio de nuestra profession" (Morales, 2006: 266).

Sin el padre Valdivia, las cosas volverían lentamente a su cauce anterior. Asimismo, se repite que los jesuitas deben mantenerse alejados de la Guerra Defensiva, y preocuparse sólo de los asuntos estrictamente religiosos. Ahora bien, la Guerra Defensiva en sí, planteaba un ideal religioso y misionero propio de los jesuitas, entonces ¿ por qué ese llamado a alejarse de ella? Pues porque 
no era conveniente. De tal forma, la guerra no durará mucho más. En 1626 el plan fracasó por completo y se regresó a la vieja estrategia de la guerra ofensiva tradicional. Por tanto, ante el inminente fracaso, la Compañía debe preocuparse de recuperar las confianzas perdidas y mantener los buenos términos con los vecinos.

Quizás uno de los principales problemas del plan de Valdivia es que no consideró a los vecinos. Tanto en Paraguay, como en China, los planes jesuitas desarrollados ahí o no contaban con vecinos cercanos que se interesaran en ellos, o se crearon a partir de un acercamiento con las élites (sobre todo Ricci). En cambio, Valdivia no sólo les quitó su sustento económico al terminar con el servicio personal, sino que lo hizo sin preguntar, sin convencer de manera "ciudadana" a los vecinos. Ante esto, lógico era que reaccionaran de manera negativa ante el plan. Se presenta nuevamente aquí una idea esbozada ya anteriormente, la de la Compañía como un "vecino" más, y que, si bien es aceptada por los otros vecinos, debe también saber actuar de manera cívica. El problema existiría cuando la acción civil y la acción religiosa de los jesuitas se encuentren y no sean compatibles, el cual habría sido el caso de Valdivia. Las relaciones vecinales no sólo son útiles para conseguir donaciones de tierras y dinero, sino también para implantar políticas; después de todo, el Rey está muy lejos y los vecinos muy cerca.

Tras el fin de la Guerra Defensiva, no existirían mayores conflictos entre jesuitas y vecinos. Por el contrario, y como se ha visto en capítulos anteriores, la orden pareció no perder nunca el completo favor de Santiago, y recuperó rápidamente lo perdido con el plan de Valdivia. De esta forma es como el Colegio Máximo llegó al año 1647, año en que se pondría a prueba el favor vecinal y la capacidad jesuita para posicionarse como una orden principal en Santiago.

\section{Conclusiones}

La interacción entre los jesuitas y los vecinos de Santiago fue, desde un principio, favorable para el desarrollo de la orden religiosa. El apoyo mostrado por los vecinos de la ciudad, así como las grandes donaciones hechas por ellos, fueron fundamentales para la mantención de la orden, así como para tomar la decisión de crear un colegio en Santiago. Asimismo, las donaciones se mantuvieron de manera constante durante los primeros años de la orden en Santiago, lo que ayudó a posicionarse de manera estable en el territorio. Asimismo, variados testimonios dan cuenta de lo agradecidos que muchos vecinos se encontraban con la Compañía por los distintos servicios que ésta les prestaba, ya fuera por los años de escuela, por cuidarlos durante la vejez, o por las misas que deberán cantarles tras su muerte. Así, la Compañía logró mantener una relación buena y estable 
con la mayoría de los vecinos, comportándose en muchos casos como un vecino más dentro de la ciudad, y participando de la civilidad de Santiago. Sobre todo, el rol educativo de la Compañía, así como la experticia de sus miembros en distintos tópicos, sería reconocido por los vecinos, quienes verían en ellos a una orden a la cual recurrir para resolver distintos problemas en la ciudad.

El único conflicto que se pudo considerar grave fue la Guerra Defensiva, pues debido a esta estrategia gran parte de los vecinos de Santiago comenzaron a criticar a la Compañía, y en muchos casos la excluyeron de sus actividades. Esto se habría debido a dos razones principales, sin considerar la pérdida del ingreso por el servicio personal. La primera, la incomprensión de los vecinos de Santiago para ver a la orden misionera y a la orden educadora como un todo unificado, en lugar de verla como funciones distintas y descartables en favor de una u otra. Y, en segundo lugar, la incomprensión de Luis de Valdivia para tratar con los vecinos de la ciudad, quienes se vieron sorprendidos por un plan que no les fue consultado en ningún momento. Básicamente, la incomprensión mutua causó el conflicto más grave que la Compañía vivió en estos primeros años.

\section{Referencias bibliográficas}

\section{Fuentes primarias}

\section{a) Archivos}

Archivo Nacional Histórico de Chile, Fondo Jesuitas de Chile, Vol. 124, 119, 93, 39.

Archivo Nacional Histórico de Chile, Fondo Real Audiencia, Vol. 2114.

Archivo del Arzobispado de Santiago, Fondo de Gobierno, Vol. 25.

\section{b) Documentos impresos}

Díaz Blanco, J. M. (2011). El Alma en la Palabra. Escritos Inéditos del P. Luis de Valdivia. Santiago de Chile: Ediciones Universidad Alberto Hurtado.

Egaña, A. de (ed.) (1970). Monumenta Peruana. Roma: Monumenta Historica Societatis lesu, Tomo V.

Egaña, A. de (ed.) (1974). Monumenta Peruana. Roma: Monumenta Historica Societatis lesu, Tomo VI.

Medina, J. T. (1900). Colección de Historiadores de Chile y de Documentos Relativos a la Historia Nacional. Santiago de Chile: Imprenta Elzeviriena, Tomo XXI. 
Medina, J. T. (1901). Colección de Historiadores de Chile y de Documentos Relativos a la Historia Nacional. Santiago de Chile: Imprenta Elzeviriena, Tomo XXIV.

Medina, J. T. (1901). Colección de Historiadores de Chile y de Documentos Relativos a la Historia Nacional. Santiago de Chile: Imprenta Elzeviriena, Tomo XXV.

Medina, J. T. (1902). Colección de Historiadores de Chile y de Documentos Relativos a la Historia Nacional. Santiago de Chile: Imprenta Elzeviriena, Tomo XXVIII.

Medina, J. T. (1905). Colección de Historiadores de Chile y de Documentos Relativos a la Historia Nacional. Santiago de Chile: Imprenta Elzeviriena, Tomo XXXI.

Morales, Martín María (ed.) (2005). A mis manos ha llegado: Cartas de los PP. Generales a la Antigua Provincia del Paraguay (1608-1639). Madrid: Universidad Pontificia Comillas.

\section{Fuentes secundarias}

\section{a) Artículos y capítulos de libros}

Chauca, R. (2016). "Sobre letrados chinos y bogas amazonicos: La participación indígena en la producción del conocimiento cartográfico y geográfico jesuita en Asia y América", en Revista de Historia y Geografía. № 34, pp. 19-41.

De Tezanos, A. (2014). "El isomorfismo de las bibliotecas jesuitas (siglos XVI XVIII)", en Revista de Historia Social y de las Mentalidades. Vol. 18, № 2, pp. $105-139$.

Gaune Corradi, R. (2011). "Organizando el otro deseo de las Indias: la expansión periférica de la Compañía de Jesús en América (Chile, 1568-1593", en Estudios Humanisticos. Historia. № 10, pp. 297 - 320.

Ginzburg, C. (2014). "Aun Sobre los Ritos Chinos: Documentos Viejos y Nuevos", en Formas de Control y Disciplinamiento. Chile, América y Europa, siglos XVIXIX, editado por Verónica Undurraga y Rafael Gaune. Santiago de Chile: Uqbar Editores, pp. 301-315.

Gutiérrez, E. (2014). "Desde el colegio Máximo a la Biblioteca Nacional: usos, y resignificaciones de una biblioteca en Chile (1767-1813)", en Revista de Historia Social y de las Mentalidades. Vol. 18, № 2, pp. 141-166.

Hanisch E., W. (1962-1963). "En torno a la Filosofía en Chile", en Historia. Pontificia Universidad Católica de Chile: Instituto de Historia, Vol. 2, pp. 7-117.

Valenzuela, J. (1992). "La percepción del tiempo en la colonia: poderes y sensibilidades", en Mapocho, № 32, pp. 225-244. 
b) Libros

Díaz Blanco, J. M. (2010). Razón de Estado y Buen Gobierno. La Guerra Defensiva y el Imperialismo Español en Tiempos de Felipe III. Sevilla: Universidad de Sevilla.

Enrich, F. (1891). Historia de la Compañía de Jesús en Chile. Barcelona: Imprenta de Francisco Rosal.

Gaune Corradi, R. (2016). Escritura y salvación. Cultura misionera jesuita en tiempos de Anganamón, siglo XVII. Santiago de Chile: Ediciones Universidad Alberto Hurtado.

Hanisch E., W. (1974). Historia de la Compañía de Jesús en Chile (1593-1955). Buenos Aires, Santiago de Chile: Editorial Francisco de Aguirre.

Kort, E. H., S.J. (1968). Spanish Policy in Colonial Chile. The Struggle for Social Justice, 1535 - 1700. Stanford: Stanford University Press.

Medina, J. M. (1906). Diccionario Biográfico Colonial de Chile. Santiago de Chile: Imprenta Elzeviriana.

O'Malley, J. W. (1993). Los Primeros Jesuitas. Bilbao: Ediciones Mensajero.

Tampe, E. (2010). En la huella de San Ignacio: Semblanzas de jesuitas en Chile, Tomo I, 1593 - 1767. Santiago de Chile: Ediciones Revista Mensaje. 